\title{
Association of Ischemic Heart Disease Assessed by Radionuclide Myocardial Perfusion Imaging with Bone Mineral Density Measurements by Dual-Energy X-Ray Absorptiometry and Serum Vitamin D Deficiency
}

\author{
Sina Izadyar, Saeed Farzanehfar, ${ }^{2}$ Mina Ranji Amjad,,$^{3,}{ }^{*}$ Mehrshad Abbasi, ${ }^{2}$ Alireza Emami Ardekani, \\ Babak Fallahi, ${ }^{3}$ Armaghan Fard Esfehani, ${ }^{3}$ Javad Esmaeli, ${ }^{2}$ Fariba Akhzari, ${ }^{4}$ and Parham Geramifar ${ }^{3}$ \\ ${ }^{1}$ Department of Nuclear Medicine, Imam Khomeini Hospital Complex, Tehran University of Medical Sciences, Tehran, Iran \\ ${ }^{2}$ Research Center for Nuclear Medicine, Valiasr Hospital, Tehran University of Medical Sciences, Tehran, Iran \\ ${ }^{3}$ Research Center for Nuclear Medicine, Shariati Hospital Tehran University of Medical Sciences, Tehran, Iran \\ ${ }^{4}$ Research Center for Nuclear Medicine, Sina Hospital, Tehran University of Medical Sciences, Tehran, Iran \\ "Corresponding author: Mina Ranji Amjad, Research Center for Nuclear Medicine, Shariati Hospital Tehran University of Medical Sciences, Tehran, Iran. Tel: +98-9143130247; \\ +98-2188633333, Fax: +98-2188026905, E-mail: mn_amjad@yahoo.com
}

Received 2016 April 13; Revised 2016 September 14; Accepted 2016 September 30.

\begin{abstract}
Background: Because of the increasing prevalence of both ischemic heart diseases and vitamin D deficiency and also due to recent evidences on association between these two phenomena, it is vital to clarify the association of ischemic heart disease with vitamin D deficiency and low bone mass.

Objectives: The aim of the present study was to assess the relationship between low serum vitamin D and low bone mass measured by dual-energy X-ray absorptiometry (DEXA) with ischemic heart disease assessed by the functional radionuclide myocardial perfusion imaging (MPI).

Patients and Methods: In this cross-sectional study, 204 consecutive patients aged older than 50 years who were candidates for MPI were included. Blood sample was extracted to measure the level of serum 25-OH vitamin D using a special kit(IDS kit). Then, the patients were assessed by MPI. Within a month of myocardial perfusion scanning, subjects underwent bone mineral density (BMD) measurements by DEXA method.

Results: There was no significant difference in serum level of vitamin D between patients with normal and those with abnormal MPI results. In addition, no significant correlation was detected between BMD and myocardial ischemia.

Conclusion: Coronary atherosclerosis may not be associated with the severity of low bone mass or level of vitamin D adequacy.
\end{abstract}

Keywords: Myocardial Ischemia, Vitamin D Deficiency, Bone Density

\section{Background}

Association between low bone mineral density (BMD) and ischemic heart disease (IHD) remains challenging. According to some recent evidence, osteoporotic patients not only face bone fracture, but also may be exposed to increased risk for brain stroke, cognitive disorders, arterial atherosclerosis, and even cardiac-related death in both men and women (1-5). However, the explaining reasons for this relationship remain unknown. Due to some common risk factors for both atherosclerosis and osteoporosis such as smoking, systemic inflammatory conditions, or postmenopausal status, common pathophysiological pathways for these two clinical conditions are expectable (6-9). For instance, postmenopausal osteoporotic women significantly face a higher risk for IHD compared to other age subgroups of women (10-12).
One of the main causes of osteoporosis is vitamin D deficiency frequently due to inadequate sun exposure, low dietary intake, low physical activity, or air pollution (11, 12). It has been well shown that vitamin D deficiency may have deleterious effects on cardiovascular system (1315). Vitamin D receptors are widely distributed in different tissues including smooth muscles of vessels, endothelium, and also cardiomyocytes. In vivo study could reveal that 25-hydroxy vitamin D may directly inhibit expression of genes related to smooth muscle proliferation and cardiomyocytes as well as inhibit secretion of cytokines from lymphocytes (16-18). Also, some experimental studies on animal models show that lack of vitamin D receptor activators can result in hypertension, and left ventricular hypertrophy (19). Moreover, vitamin D deficiency may be accompanied by an increased level of parathyroid hormone lead- 
ing to insulin resistance that is a major cause of diabetes mellitus, activation of inflammatory processes as well as coronary atherosclerosis (20-22). Because of the increasing trend of vitamin D deficiency and also osteoporosis, it is vital to clarify the association between IHD and vitamin D deficiency.

\section{Objectives}

The aim of the present study was to assess this relationship by a functional method using radionuclide myocardial perfusion imaging (MPI). In previous studies, this association was assessed using anatomical methods such as coronary angiography, measuring coronary calcification, and also CT angiography. However, in the present study, functional method of MPI was employed to assess the cardiac function physiologically in addition to anatomically.

\section{Patients and Methods}

\subsection{Participants}

In this cross-sectional study, the consecutive patients aged older than 50 years suspected of IHD and candidates for MPI at Imam Khomeini and Shariati hospitals between September 2012 and October 2013 were included into the study. The main exclusion criteria were history of fracture or prosthesis of the neck of the femur, history of fracture or surgery on the vertebral column, any deformity that inhibited performing BMD measurements, severe degenerative changes in the femoral head or lumbar vertebral column, previous history of use of corticosteroids (at least $15 \mathrm{mg}$ for 3 months within two recent years), hyperthyroidism, antiepileptic drugs, or levothyroxine.

\subsection{Test Methods}

Baseline information including demographics, medical history and medications were collected by interviewing or by reviewing the recorded files. Blood sample was extracted to measure the level of serum $25-\mathrm{OH}$ vitamin D using a special kit (IDS kit). Based on the reference measurement and definition, vitamin D deficiency is defined as serum 25-OH vitamin D level less than $10 \mathrm{ng} / \mathrm{mL}$, vitamin $\mathrm{D}$ is defined as insufficient when serum level is more than $10 \mathrm{ng} / \mathrm{mL}$ but less than $30 \mathrm{ng} / \mathrm{mL}$ and sufficient vitamin $\mathrm{D}$ is defined when the serum level is more than $30 \mathrm{ng} / \mathrm{mL}$. The patients were then assessed by perfusion scan using 2 day 99 mTC-Sestamibi MPI protocol with appropriate exercise or pharmacological stress test and a dual head ADAC gamma camera to assess presence, extension and severity of cardiac ischemia by qualitative and semi-quantitative methods according to Table 1 . Normal MPI is considered when there is no perfusion defect on stress phase and the summed stress score (SSS) is less than 4 in quantitative analysis. Mild ischemia is defined by mild reversible hypo perfusion in one coronary artery territory and $4 \leq$ SSS $\leq$ 8. Moderate ischemia is defined by mild to moderate reversible hypo perfusion in more than two myocardial segments but in one coronary artery territory and $9 \leq \mathrm{SSS} \leq 12$. Severe ischemia is defined by moderate to severe reversible hypo perfusion in more than two coronary artery territories or partially reversible perfusion defect and $13 \leq$ SSS.

Within a month of MPI, subjects underwent bone densitometry by Dual-energy X-ray absorptiometry (DEXA) of the bilateral femoral heads as well as lumbar vertebrae using HOLOGIC or LEXXOS bone densitometer. According to the world health organization (WHO) definitions based on bone density levels (Lowest T-score), the status of BMD of the patients was classified as normal, osteopenia, and osteoporosis (Table 2).

\subsection{Ethical Statement}

Participants were free to take part in the study and all of them signed informed consent forms. The study protocol conforms to the ethical guidelines of the 1975 Declaration of Helsinki as reflected in a prior approval by the human research committee of Tehran University of Medical Sciences.

\subsection{Statistical Analysis}

Results were presented as mean \pm standard deviation (SD) for quantitative variables and were summarized by frequency (percentage) for categorical variables. Continuous variables were compared using t test. Whenever the data did not appear to have a normal distribution or when the assumption of equal variances was violated across the study groups, the corresponding data was transformed appropriately (i.e. vitamin D values had significant skewness and were transformed to the $\mathrm{Ln}$ ). Categorical variables were compared using chi-square test. Binary logistic model was designed to determine the correlation of osteoporosis with IHD (binominal as dependent variable) with sex and BMI as covariates. For statistical analysis, statistical software SPSS version 17 for windows (SPSS Inc., Chicago, IL) was used. P values of 0.05 or less were considered statistically significant.

\section{Results}

\subsection{Participants}

Totally, 204 patients (131 women and 73 men; mean age, $59 \pm 7$ years; range, 50 to 80 years) were assessed. Baseline characteristics of patients and prevalence of IHD risk factors are summarized in Table 3. 
Table 1. Comparative Categorization of Extent of Exercise Myocardial Perfusion Abnormalities (Modified from Zaret Bl, “Clinical Nuclear Cardiology", $4^{\text {th }}$ Edition, 2010, Mosby Elsevier)

\begin{tabular}{lccc}
\hline & & Defect Extent \\
\cline { 2 - 4 } & Small & Moderate \\
\hline Vascular territories & $<1$ & $1-2$ & Large \\
Summed stress score & $4-8$ & $9-13$ & 2 or 3 \\
Polar maps (\% of LV) & $<10 \%$ & $10 \%-20 \% \quad 20 \% \quad$ \\
\hline
\end{tabular}

Table 2. World Health Organization Definitions Based on Bone Density Levels

\begin{tabular}{ll}
\hline Level & Definition \\
\hline Normal & Bone density is within 1 SD $(+1$ or -1$)$ of the young adult mean. \\
\hline Osteopenia & Bone density is between 1 and 2.5 SD below the young adult mean $(-1$ to -2.5 SD). \\
Osteoporosis & Bone density is 2.5 SD or more below the young adult mean (-2.5 SD or lower). \\
\hline Severe (established) osteoporosis & Bone density is more than 2.5 SD below the young adult mean, and there have been one or more osteoporotic fractures. \\
\hline Abbreviation: SD, standard deviation. & \\
\hline
\end{tabular}

Table 3. Baseline Characteristics of Patients According to IHD Risk Factors ${ }^{\mathrm{a}}$

\begin{tabular}{|c|c|}
\hline IHD Risk Factors & No. (\%) \\
\hline Male & $73(35.8)$ \\
\hline Diabetes mellitus & $45(22.1)$ \\
\hline Hyperlipidemia & $71(34.8)$ \\
\hline Moderate hypertension & $58(28.4)$ \\
\hline Smoking & $29(14.2)$ \\
\hline Family history of IHD & $46(22.5)$ \\
\hline BMI more than 30 & $61(30)$ \\
\hline Total patients & $204(100)$ \\
\hline
\end{tabular}

Abbreviation: IHD, ischemic heart disease.

${ }^{a}$ Values are expressed as number or percentage.

\subsection{Test Results}

Among the total 204 patients, 141 (69.1\%) were diagnosed as normal myocardial perfusion, 16 (7.8\%) had mild ischemia, 29 had moderate ischemia (14.3\%), and 18 (8.8\%) had severe ischemia in MPI.

The mean level of serum vitamin D was $22.7 \pm 16.7$ $\mathrm{ng} / \mathrm{mL}$ ranged 3.3 to $129 \mathrm{ng} / \mathrm{mL}$. Distribution of serum vitamin D level is shown in Figure 1. Overall, normal BMD, osteopenia, and osteoporosis were found in 24 (11.8\%), 95 (46.6\%), and 85 (41.7\%), respectively.

There was no significant difference in the serum level of vitamin D between patients with normal MPI and those with abnormal scan results $(22 \pm 17 \mathrm{ng} / \mathrm{mL}$ versus $25 \pm 16$ $\mathrm{ng} / \mathrm{mL}, \mathrm{P}=0.29)$. Overall no significant correlation was detected between BMD and IHD (Table 4); however, there was a significant difference in the mean BMD at lumbar vertebrae between patients with normal and abnormal MPI $\left(0.86 \pm 0.18 \mathrm{~g} / \mathrm{cm}^{2}\right.$ versus $\left.0.93 \pm 0.19 \mathrm{~g} / \mathrm{cm}^{2}, \mathrm{P}=0.023\right)$, but there was no significant difference in the mean BMD in the right and left femurs (Table 5).

We designed a binary logistic regression model with the result of MPI (normal vs. abnormal) as dependent variable and the BMD strata, sex and BMI as independent factors. MPI was not associated with the osteoporosis status (Odd's Ratio = 1.1 CI95\%:0.6 - 1.8), nevertheless sex was associated with the results of MPI. Odd's ratio for males to have 
Table 4. Association Between Vitamin D Level and BMD Strata and the Result of MPI

\begin{tabular}{|c|c|c|c|c|c|}
\hline & Normal MPI & Abnormal MPI & Total & OR & Significance Level $^{\mathbf{a}}$ \\
\hline \multicolumn{5}{|l|}{ Vitamin D level } & \multirow{4}{*}{0.02} \\
\hline Intoxication & $1(0.6)$ & 0 & $1(0.5)$ & & \\
\hline Sufficient & $32(20.5)$ & $19(39.6)$ & $51(25)$ & Reference & \\
\hline Insufficient & $87(55.8)$ & $16(33.3)$ & $103(50.5)$ & 0.31 & \\
\hline Deficient & $36(23.1)$ & $13(27.1)$ & $49(24)$ & 0.61 & 0.3 \\
\hline \multicolumn{5}{|l|}{ BMD status } & \multirow{4}{*}{0.68} \\
\hline Normal & $19(12.2)$ & $5(10.4)$ & $24(11.8)$ & Reference & \\
\hline Osteopenia & $70(44.9)$ & $25(52.1)$ & $95(46.6)$ & 1.36 & \\
\hline Osteoporosis & $67(42.9)$ & $18(37.5)$ & $85(41.7)$ & 1.02 & \\
\hline
\end{tabular}

Abbreviations: BMD, bone mineral density; MPI, myocardial perfusion imaging.

${ }^{a}$ Indicates P value.

Table 5. Vitamin D Level and the Value of BMD in Different Sites Based on MPI Results

\begin{tabular}{|c|c|c|c|c|}
\hline & Normal MPI & Abnormal MPI & Total & Significance Level ${ }^{\mathbf{a}}$ \\
\hline Vitamin D level & $17.1(12.9)$ & $25.2(17.7)$ & $22.7(16.8)$ & 0.29 \\
\hline BMD; right femur & $0.7(0.1)$ & $0.7(0.1)$ & $0.7(0.1)$ & 0.68 \\
\hline BMD; left femur & $0.7(0.1)$ & $0.7(0.1)$ & $0.7(0.1)$ & 0.84 \\
\hline BMD; lumbar spine & $0.7(0.1)$ & $0.9(0.2)$ & $0.9(0.2)$ & 0.02 \\
\hline
\end{tabular}

Abbreviations: BMD, bone mineral density; MPI, myocardial perfusion imaging.

${ }^{a}$ Indicates P value.

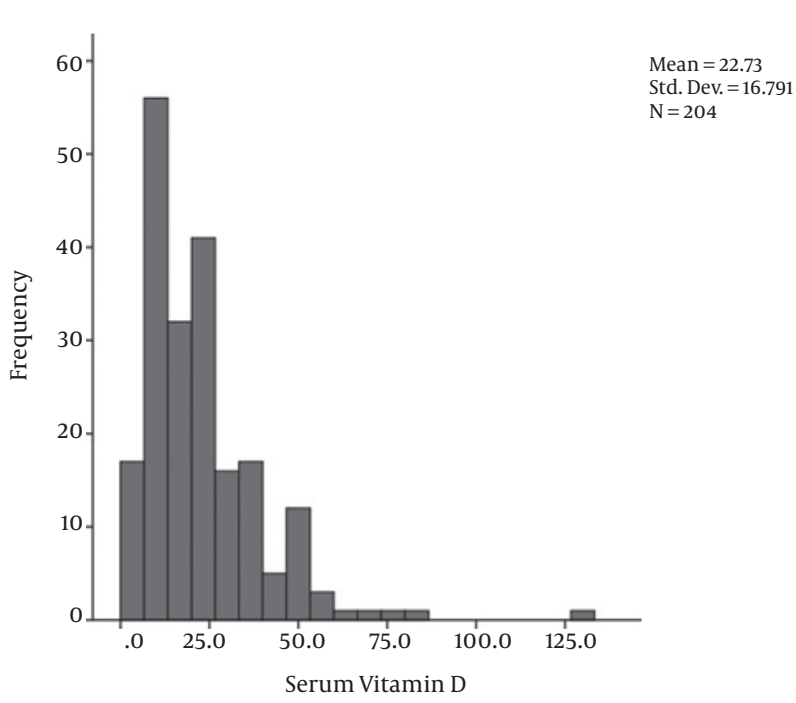

Figure 1. Overall distribution of serum vitamin D level

abnormal MPI $=2.5($ CI95\%: $1.2-5.2 ; \mathrm{P}=0.01)$.

\section{Discussion}

In initial studies on the association between cardiovascular disorders and low bone mineral density, this association had been suggested in women. On the other hand, coronary atherosclerosis and osteoporosis are potentially age dependent. However, by adjusting age as an independent factor, the relationship between atherosclerosis and osteoporosis converted to an insignificant relation. For instance, Tekin Go and colleagues (3) showed association between the presence of IHD based on angiography reports and osteoporosis in women, but by adjustment for age variable, this association was not confirmed. Bakhivera et al. (23) also showed no independent association between atherosclerosis and osteoporosis in the lumbar vertebrae and femoral neck. Kammerer et al. (24) also showed that the obtained association between atherosclerosis and osteoporosis could be strongly dependent on patients' age. Kim et al. (25) study, although univariate analysis between coronary calcium score and T score was significant, this significance was not shown in multivariate regression modeling.

In most studies, vitamin D deficiency introduced as a 
well-known risk factor for ischemic heart disease, particularly when accompanied by other coronary risk factors. Non-significant association between these two parameters may be due to the variations in the definition of cutoff points for normal and abnormal levels of vitamin D. In some studies and using the definition by the institute of medicine (IOM) (17), the level of vitamin D $>20 \mathrm{ng} / \mathrm{mL}$ was considered as the adequate level; while the guideline of the international society of endocrinology has recommended the cutoff $>30 \mathrm{ng} / \mathrm{mL}$ as the adequate level for this vitamin (26). In addition, there is no definitive Vitamin D serum level cutoff to differentiate high risk patients for IHD from normal coronary conditions.

Another limitation of the present study was serum vitamin D level variation in different seasons (i.e. highest in August and lowest in February); this physiologic phenomenon lead to change in one patient's serum vitamin $\mathrm{D}$ level when measured in summer and winter $(14,15)$. In this cross-sectional study the potential seasonal effect may be ignored. Also, this association can be affected by patients' physical functioning and also by heart failure functional class that were not considered in the present study. On the other hand some patients with normal MPI may be in increased risk for IHD (such as the patients with transient left ventricular dilatation) and in case of balanced multi-vessel disease, myocardial perfusion impairment may not be detected. These evidences may explain observed paradoxical findings on relationship between coronary atherosclerosis and presence of osteoporosis.

\subsection{Conclusion}

This study did not show association between IHD assessed by MPI study and osteoporosis or vitamin D deficiency. The association could be potentially affected by some confounders including age, seasonal changes, dietary patterns, or other coronary risk factors. Therefore, we recommend adjustment for these confounders in further studies.

\section{Acknowledgments}

This research was supported by Tehran University of Medical sciences \& health services grant no. 15990. The authors would like to express their sincere thanks to the technologists of the research institute for nuclear medicine, Ms. Darvishha and Ms. Asadi for their fruitful cooperation.

\section{Footnotes}

Authors' Contribution: None declared.

Financial Disclosure: None declared.
Funding/Support: None declared.

\section{References}

1. Sinnott B, Syed I, Sevrukov A, Barengolts E. Coronary calcification and osteoporosis in men and postmenopausal women are independent processes associated with aging. Calcif Tissue Int. 2006;78(4):195-202. doi: 10.1007/s00223-005-0244-z. [PubMed: 16604285].

2. Hak AE, Pols HA, van Hemert AM, Hofman A, Witteman JC. Progression of aortic calcification is associated with metacarpal bone loss during menopause: a population-based longitudinal study. Arterioscler Thromb Vasc Biol. 2000;20(8):1926-31. [PubMed: 10938013].

3. Tekin GO, Kekilli E, Yagmur J, Uckan A, Yagmur C, Aksoy Y, et al. Evaluation of cardiovascular risk factors and bone mineral density in post menopausal women undergoing coronary angiography. Int J Cardiol. 2008;131(1):66-9. doi: 10.1016/j.ijcard.2007.09.002. [PubMed: 18222554].

4. Kiel DP, Kauppila LI, Cupples LA, Hannan MT, O’Donnell CJ, Wilson PW. Bone loss and the progression of abdominal aortic calcification over a 25 year period: the Framingham Heart Study. Calcif Tissue Int. 2001;68(5):271-6. [PubMed: 11683533].

5. Tanko LB, Bagger YZ, Christiansen C. Low bone mineral density in the hip as a marker of advanced atherosclerosis in elderly women. Calcif Tissue Int. 2003;73(1):15-20. [PubMed: 14506949].

6. Schulz E, Arfai K, Liu X, Sayre J, Gilsanz V. Aortic calcification and the risk of osteoporosis and fractures. J Clin Endocrinol Metab. 2004;89(9):4246-53. doi:10.1210/jc.2003-030964. [PubMed:15356016].

7. Uyama O, Yoshimoto Y, Yamamoto Y, Kawai A. Bone changes and carotid atherosclerosis in postmenopausal women. Stroke. 1997;28(9):1730-2. [PubMed: 9303016].

8. Browner WS, Seeley DG, Vogt TM, Cummings SR. Non-trauma mortality in elderly women with low bone mineral density. Study of Osteoporotic Fractures Research Group. Lancet. 1991;338(8763):355-8. [PubMed: 1677708].

9. von der Recke P, Hansen MA, Hassager C. The association between low bone mass at the menopause and cardiovascular mortality. Am J Med. 1999;106(3):273-8. [PubMed: 10190374].

10. Kado DM, Browner WS, Blackwell T, Gore R, Cummings SR. Rate of bone loss is associated with mortality in older women: a prospective study. J Bone Miner Res. 2000;15(10):1974-80. doi: 10.1359/jbmr.2000.15.10.1974. [PubMed:11028450].

11. Trivedi DP, Khaw KT. Bone mineral density at the hip predicts mortality in elderly men. Osteoporos Int. 2001;12(4):259-65. doi: 10.1007/s001980170114. [PubMed: 11420774].

12. Center JR, Nguyen TV, Schneider D, Sambrook PN, Eisman JA. Mortality after all major types of osteoporotic fracture in men and women: an observational study. Lancet. 1999;353(9156):878-82. doi:10.1016/S01406736(98)09075-8. [PubMed: 10093980].

13. From AM, Hyder JA, Kearns AM, Bailey KR, Pellikka PA. Relationship between low bone mineral density and exercise-induced myocardial ischemia. Mayo Clin Proc. 2007;82(6):679-85. [PubMed: 17550747].

14. Ku YC, Liu ME, Ku CS, Liu TY, Lin SL. Relationship between vitamin D deficiency and cardiovascular disease. World J Cardiol. 2013;5(9):33746. doi: 10.4330/wjc.v5.i9.337. [PubMed: 24109497].

15. Wang TJ, Pencina MJ, Booth SL, Jacques PF, Ingelsson E, Lanier K, et al. Vitamin D deficiency and risk of cardiovascular disease. Circulation. 2008;117(4):503-11. doi: 10.1161/CIRCULATIONAHA.107.706127. [PubMed: 18180395].

16. Dobnig H, Pilz S, Scharnagl H, Renner W, Seelhorst U, Wellnitz B, et al. Independent association of low serum 25-hydroxyvitamin $\mathrm{d}$ and 1,25-dihydroxyvitamin d levels with all-cause and cardiovascular mortality. Arch Intern Med. 2008;168(12):1340-9. doi: 10.1001/archinte.168.12.1340. [PubMed: 18574092]. 
17. Anderson JL, May HT, Horne BD, Bair TL, Hall NL, Carlquist JF, et al. Relation of vitamin D deficiency to cardiovascular risk factors, disease status, and incident events in a general healthcare population. Am J Cardiol. 2010;106(7):963-8. doi: 10.1016/j.amjcard.2010.05.027. [PubMed: 20854958].

18. de Boer IH, Kestenbaum B, Shoben AB, Michos ED, Sarnak MJ, Siscovick DS. 25-hydroxyvitamin D levels inversely associate with risk for developing coronary artery calcification. J Am Soc Nephrol. 2009;20(8):1805-12. doi:10.1681/ASN.2008111157. [PubMed: 19443637].

19. Nibbelink KA, Tishkoff DX, Hershey SD, Rahman A, Simpson RU. 1,25(OH)2-vitamin D3 actions on cell proliferation, size, gene expression, and receptor localization, in the HL-1 cardiac myocyte. J Steroid Biochem Mol Biol. 2007;103(3-5):533-7. doi: 10.1016/j.jsbmb.2006.12.099. [PubMed:17276054].

20. Tishkoff DX, Nibbelink KA, Holmberg KH, Dandu L, Simpson RU Functional vitamin D receptor (VDR) in the t-tubules of cardiac myocytes: VDR knockout cardiomyocyte contractility. Endocrinology. 2008;149(2):558-64. doi: 10.1210/en.2007-0805. [PubMed: 17974622].

21. Bodyak N, Ayus JC, Achinger S, Shivalingappa V, Ke Q, Chen YS, et al. Activated vitamin D attenuates left ventricular abnormalities induced by dietary sodium in Dahl salt-sensitive animals. Proc Natl Acad Sci U S A. 2007;104(43):16810-5. doi: 10.1073/pnas.0611202104. [PubMed: 17942703].
22. Wu J, Garami M, Cheng T, Gardner DG. 1,25(OH)2 vitamin D3, and retinoic acid antagonize endothelin-stimulated hypertrophy of neonatal rat cardiac myocytes. J Clin Invest. 1996;97(7):1577-88. doi: 10.1172/JCI118582. [PubMed: 8601621].

23. Bakhireva LN, Barrett-Connor EL, Laughlin GA, Kritz-Silverstein D. Differences in association of bone mineral density with coronary artery calcification in men and women: the Rancho Bernardo Study. Menopause. 2005;12(6):691-8. doi: 10.1097/01.gme.0000184422.50696.ef. [PubMed: 16278612].

24. Kammerer CM, Dualan AA, Samollow PB, Perisse AR, Bauer RL, MacCluer JW, et al. Bone mineral density, carotid artery intimal medial thickness, and the vitamin D receptor BsmI polymorphism in Mexican American women. Calcif Tissue Int. 2004;75(4):292-8. doi: 10.1007/s00223-004-0215-9. [PubMed:15549643].

25. Kim KI, Suh JW, Choi SY, Chang HJ, Choi DJ, Kim CH, et al. Is reduced bone mineral density independently associated with coronary artery calcification in subjects older than 50 years?.J Bone Miner Metab. 2011;29(3):369-76. doi: 10.1007/s00774-010-0229-5. [PubMed: 21069548].

26. Marcovitz PA, Tran HH, Franklin BA, O'Neill WW, Yerkey M, Boura J, et al. Usefulness of bone mineral density to predict significant coronary artery disease. Am J Cardiol. 2005;96(8):1059-63. doi: 10.1016/j.amjcard.2005.06.034. [PubMed:16214438] 